\title{
Uma pequena Europa na Serra Gaúcha: as apropriações culturais na arquitetura do espaço urbano de Gramado (RS)
}

A small Europe in the Sierra Gaúcha: cultural appropriations in the architecture of the urban area of Gramado (RS)

\author{
Daniel Luciano Gevehr \\ Faculdades Integradas de Taquara - FACCAT - Taquara - Rio Grande do Sul - Brasil
}

\section{Franciele Berti}

Faculdades Integradas de Taquara - FACCAT - Taquara - Rio Grande do Sul - Brasil

Resumo: Discute-se as apropriações culturais na arquitetura do espaço urbano de Gramado (RS). Para tanto, por meio de visita de campo, foram mapeadas 10 edificações. Na oportunidade, empregando a observação sistemática, realizou-se os registros fotográficos dos lotes em análise. Tencionando ir ao encontro da origem da difusão do estilo arquitetônico da cidade, adotou-se a coleta de dados de fonte documental, envolvendo registros de obras que narram a história do município [elaboradas por moradores de Gramado]. Os resultados evidenciaram que embora a migração italiana tenha sido mais quantitativamente mais expressiva na região, percebe-se a busca por uma identidade arquitetônica vinculada à etnia germânica. Este direcionamento da estética citadina parece estar atrelado à elite germânica que adquiriu terras em Gramado no final da década de 1930, bem como a um personagem histórico [descente de imigrantes germânicos] diretamente ligado ao setor turístico da região.

Palavras-chave: Imigração. Arquitetura. Serra Gaúcha.

\begin{abstract}
Cultural appropriations are discussed in the urban space architecture of Gramado (RS). To do so, through a field visit, 10 buildings were mapped. At the opportunity, using the systematic observation, the photographic records of the lots under analysis were carried out. Intending to go to the origin of the diffusion of the architectural style of the city, it was adopted the collection of data from documentary source, involving records of works that narrate the history of the municipality [elaborated by residents of Gramado]. The results showed that although the Italian migration was more quantitatively more expressive in the region, one can perceive the search for an architectural identity linked to the Germanic ethnicity, this direction of the urban aesthetics seems to be linked to the German elite who acquired land in Gramado at the end of 1930s, as well as to a historical personage [descendant of Germanic immigrants] directly connected to the tourist sector of the region.
\end{abstract}

Keywords: Immigration. Architecture. Serra Gaúcha. 


\section{Introdução}

O município de Gramado, localizado no nordeste do Rio Grande do Sul, foi colonizado por imigrantes italianos, germânicos e portugueses no século XIX. A cultura trazida pelos imigrantes que colonizaram a região é perceptível por meio da culinária, festas típicas e arquitetura. Tais elementos, especialmente a arquitetura, tem se constituído como uma fonte de marketing turístico para a localidade, que tem buscado uma identidade arquitetônica associada a uma tipologia de colonização, neste caso, germânica.

Com uma população de 32.273 habitantes (IBGE, 2010) em uma área de 237,827 km² (IBGE, 2015), Gramado é referência no setor turístico em âmbito nacional. O potencial turístico da localidade é cada vez mais explorado e atualmente configura-se como imagem de destino consolidado (MINISTÉRIO DO TURISMO, 2015). O município está localizado na denominada "Região das Hortênsias". Tal regionalização abrange também os municípios de Canela, São Francisco de Paula e Nova Petrópolis.

Neste estudo, de cunho qualitativo, busca-se discutir a as apropriações culturais na arquitetura do espaço urbano de Gramado (RS). Para tanto, o procedimento metodológico compreendeu, inicialmente, coleta de informações acerca da imigração germânica e italiana, no Brasil, por meio de revisão teórica. Em seguida, visando mapear as edificações que seriam selecionadas para o estudo, executou-se a visita de campo, na qual foram eleitos 10 edifícios. $\mathrm{Na}$ oportunidade, empregando a observação sistemática, realizaram-se os registros fotográficos dos lotes em análise. Tencionando ir ao encontro da origem da difusão do estilo arquitetônico da cidade, adotou-se a coleta de dados de fonte documental, envolvendo registros de obras que narram a história do município [elaboradas por moradores de Gramado].

\section{A colonização germânica e italiana no nordeste do RS}

A ocupação do território sul-rio-grandense é muito mais antiga que a história da imigração germânica e italiana. Ela se inicia, ainda no século XVIII, com as disputas territoriais, estabelecidas entre as Coroas de Espanha e Portugal na América Colonial. Daí decorre a ocupação portuguesa na região - e consequentemente na Região das Hortênsias - uma vez que, para Portugal, a presença dos colonizadores portugueses [e de forma mais efetiva, os açorianos] era fundamental, para garantir a posse efetiva da terra. Com isso, é preciso lembrar que embora a cidade de Gramado contemporânea apresente forte influência da colonização germânica e italiana, foram os portugueses os primeiros imigrantes a se estabelecerem na localidade.

A primeira iniciativa legal para regular a imigração de estrangeiros no Brasil ocorreu no início do século XIX, em 1808, por meio do Decreto de 25 de novembro, que permitiu a doação de terras [então denominadas sesmarias] aos estrangeiros residentes no Brasil. Uma década depois, o Decreto de 16 de maio de 1818 permitiu a concessão de vantagens para famílias de imigrantes europeus que se estabelecessem no país, tais como subvenção, transporte gratuito, doação de lote rural, instrumentos de trabalho, assistência médica e outras vantagens (IOTTI, 2003).

O movimento de imigração trazia em seu bojo uma série de finalidades. Por meio da atração de imigrantes, o governo pretendia ocupar áreas devolutas, incentivar o cultivo em pequenas propriedades, criar uma classe social intermediária entre os latifundiários e escravos, substituir a mão de obra escrava pela mão de obra assalariada estimular o desenvolvimento do país; além disso, tencionava-se o branqueamento da população (HERÉDIA, 2001).

No período de 1822 a 1830 foram instituídas, sob a tutela do imperador, sete colônias oficiais, dentre elas destaca-se a colônia imperial de São Leopoldo, localizada nas proximidades de Porto Alegre (capital do estado do Rio Grande do Sul). 
Sendo assim, no Rio Grande do Sul, o início da corrente imigratória de não-lusos data 1824, impulsionada por meio da Decisão n 80 de 31 de março. Por iniciativa de D. Pedro I, houve recrutamento de imigrantes no território então denominado Reino de Prússia [atualmente designado de Alemanha]. Para tanto, o discurso de atração dos germânicos estava alicerçado na promessa de benefícios que estes teriam quando chegassem. Os colonos receberiam, gratuitamente, a passagem, 77 hectares de terra, sementes, animais e subsídios (IOTTI, 2003). No período de 6 anos, aproximadamente 5.300 colonos germânicos estabeleceram-se no Rio Grande do Sul (ROCHE, 1969).

Entre 1830 e 1840 o Brasil enfrentou uma crise e durante esta década nenhuma colônia foi estabelecida no Brasil. O governo imperial retomou sua política de colonização a partir dos anos 40 . Os imigrantes italianos, por sua vez, chegaram ao Brasil entre 1874 e 1889 e no Rio Grande do Sul, fundamentalmente, após 1875, suscitado devido a conjuntura política, social e econômica desfavorável da Itália (IOTTI, 2003).

No que refere a Gramado, a intensificação dos movimentos migratórios data o século $X X$, em um período de expansão das colonas velhas geograficamente próximas a cidade, tais como Caxias do Sul, São Leopoldo, São Marcos, Sebastião do Cai, Taquara e outros (DAROS, 2012).

\section{A influência da imigração germânica e italiana na arquitetura de Gramado}

A atratividade turística de Gramado está vinculada a valorização de aspectos da cultura trazida pelos imigrantes que colonizaram o município no final do século XIX, destacando-se, neste cenário, a arquitetura europeia. Embora a colonização do município tenha sido realizada principalmente por portugueses, germânicos e italianos, de acordo com a literatura analisada (RIGATTI, 2002; DAROS, 2008), a colonização italiana é quantitativamente mais forte na região. No entanto, percebe-se a busca, particularmente por parte da municipalidade, de uma identidade arquitetônica vinculada à etnia germânica.

Até a década de 1950, a arquitetura da Avenida Borges de Medeiros [principal avenida de Gramado, que abriga ao longo dos seus 7,784 Km de extensão alguns dos principais equipamentos turísticos, como o Palácio dos Festivais, a Praça Central e o Posto de Informações Turísticas e a Igreja Matriz São Pedro] era fundamentalmente italiana. Algumas dessas edificações ainda estão instaladas na avenida, como é o caso da casa do italiano José Major Nicoletti Filho.

Construída na década de 1920, a residência do major Nicoletti foi tombada como Patrimônio Histórico e Cultural do Município em 17 de novembro de 2000, por meio da Lei № 1761. O imóvel, elevado por um muro de pedras, é construído em madeira, composto de pavimento térreo e um sótão e está localizado em uma esquina na Avenida Borges de Medeiros, considerada área nobre da cidade.

$\mathrm{Na}$ Figura 1 observa-se a referida a casa, construída em madeira sobre uma sustentação de pedras. A edificação de $68,40 \mathrm{~m}^{2}$ é constituída de longas tabuas verticais e telhado de duas águas. $O$ térreo apresenta uma ampla sacada que perpassa a fachada da edificação. Já no sótão, percebe-se uma janela e uma mansarda.

\section{Figura 1: Casa do Major José Nicoletti Filho em Gramado.}

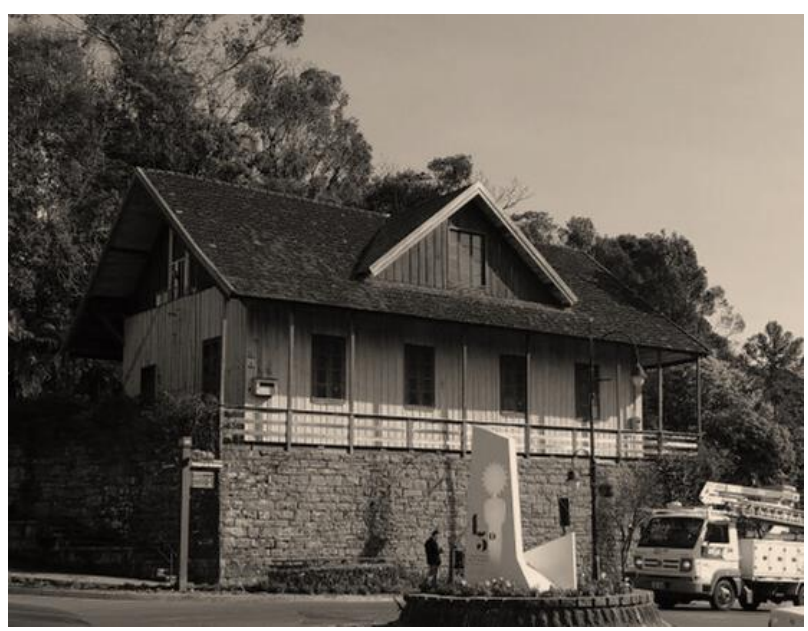

Fonte: acervo dos autores (2017).

Cabe pontuar que no início do seu desenvolvimento, Gramado estava sob o comando do 
major José Nicoletti Filho, diretamente ligado aos eventos históricos que aconteceram no município entre o final do século XIX e início do século $X X$,

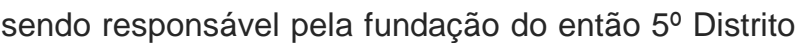
de Taquara, local onde atualmente se localiza Gramado.

Em 2009, a propriedade foi adquirida pela Prefeitura Municipal, objetivando a criação do Museu Casa do Major José Nicoletti Filho. Em 2010, por meio do Projeto de Lei № 032, foi criado o referido espaço museológico, entretanto, deste então, o projeto tem evoluído vagarosamente. De acordo com informação veiculada pelo Jornal de Gramado (2015), não foram cumpridas as melhorias do cronograma inicial da obra da revitalização da residência, que deveriam ter ocorrido em 2013.

Nas proximidades da antiga residência do major - apresentada acima - verifica-se um restaurante, instalado em um casarão construído na década de 1920 por uma família de descendência italiana. O próprio nome do restaurante remete a cultura italiana, tendo em vista que parte dele é denominado "trattoria", que, na tradição italiana, refere-se a pequenas casas familiares que oferecem pratos típicos regionais.

$\mathrm{Na}$ Figura 2 vemos 0 casarão com características típicas das construções dos imigrantes italianos, construído com pedra e madeira, longa sacada frontal e sótão.

Figura 2: Restaurante italiano no centro de Gramado.

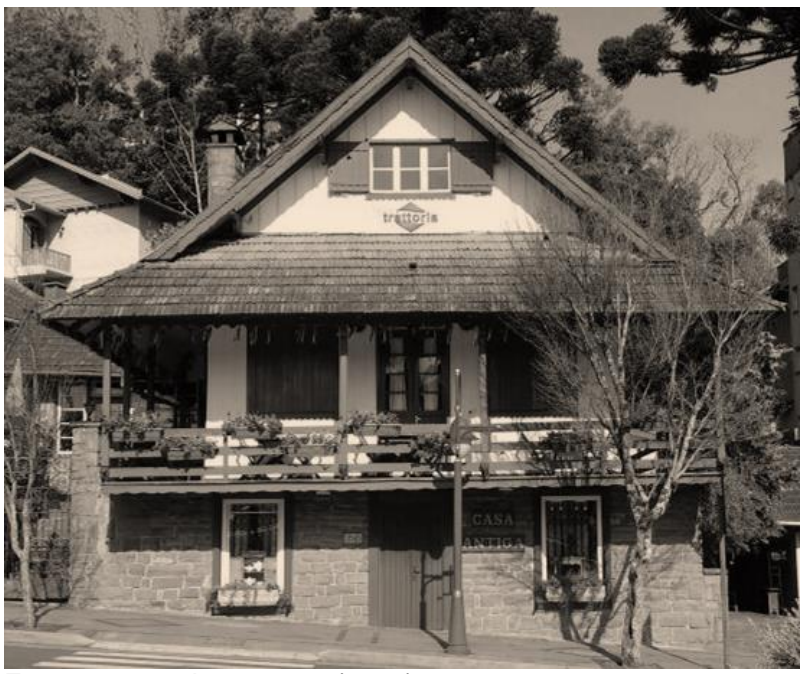

Fonte: acervo dos autores (2017).
Conforme relata a memorialista Daros (2008), entre as décadas de 1950 e 1960, identificou-se uma nova formação da avenida, tendo em vista que a arquitetura predominantemente italiana foi substituída, gradativamente, pela arquitetura mista, mas de forte inspiração germânica. Tal panorama foi intensificado pelo poder público, por meio do incentivo da construção de uma identidade arquitetônica para Gramado, refletida, também, no Plano Diretor de Desenvolvimento Integrado (PDDI), por meio de diversas normas e diretrizes que versam sobre 0 "estilo arquitetônico predominante".

Segundo o PDDI (2014), o município, em todas as zonas de uso, tem o direto de exigir que as construções apresentem as "características arquitetônicas predominantes" da cidade. Para tanto, por meio das suas secretarias e com a assistência de historiadores, associação de profissionais da construção civil, conselho de desenvolvimento rural e outros profissionais, realiza-se estudo técnico para identificar as características que devem ser mantidas. Neste sentido, conforme o PDDI (2014), são observados aspectos relacionados à colonização da cidade, tais como arquitetura, cultura, costumes, tradições, floreiras, ajardinamento, entre outros. Já as obras públicas deverão, necessariamente, apresentar o estilo arquitetônico estipulado.

De acordo com a Secretaria de Planejamento, Urbanismo, Publicidade e Defesa Civil de Gramado (2017) a prefeitura não dispõe de um documento que descreva oficialmente quais características arquitetônicas devam ser seguidas, no entanto, a utilização de telhado tradicional, materiais naturais [como madeira e pedra], dispensar o uso excessivo de vidros e acrílicos, favorecem o enquadramento da obra no estilo arquitetônico exigido pela municipalidade.

A inspiração no estilo bávaro é representativa nas construções gramadenses, sendo destacado pelo poder público municipal como o "estilo das casas de Gramado" (GRAMADO, 1987, p. 133). A tendência pode ser observada nas principais edificações do município, como a Prefeitura Municipal, o Palácio dos Festivais, instituições financeiras, na Empresa 
Brasileira de Correios e Telégrafos (Correios), estação rodoviária, hotéis e em outras construções comerciais e residenciais. O referido estilo tem seu embasamento na herança cultural dos imigrantes germânicos. A madeira, abundante na região dos climas frios, é aproveitado na construção das casas que relembram as residências europeias, cujos telhados de duas águas fortemente inclinados facilitam o deslizamento da neve, evitando o desabamento destes (GRAMADO, 1987).

De acordo com registros encontrados em obras que narram a história de Gramado, a construção que influenciou a disseminação desta estética para o município é a casa de Oscar Knorr, construída em 1940, considerada pioneira no estilo bávaro da região (GRAMADO, 1987), tal influência parece estar associada à proximidade de Oscar Knorr com o setor turístico gramadense.

Ao completar 17 anos, Oscar Knorr, cujo pai era imigrante germânico, transferiu-se de Porto Alegre para a Alemanha, tendo como objetivo prosseguir com seus estudos, onde permaneceu por quase seis anos. Na década de 1940 regressou diversas vezes para a Europa, o que permitiu, nas palavras da escritora Ilga Knorr (1995, p. 109), "aperfeiçoar seu senso estético" e nutrir sua inspiração para o estilo de casa que construiria em Gramado, anos depois. A "Mansão Knorr", como ficou conhecida a residência edificada por Oscar no alto da cidade, deveria lembrar a terra de origem dos imigrantes que hoje formam a população da Serra Gaúcha. Neste contexto, a casa fora construída obedecendo ao estilo bávaro, com paredes revestidas em madeira; a tinta para os afrescos era oriunda da Europa; já os motivos florais, que decoravam a casa, foram pintados por um artista suíço (KNORR, 1995).
Figura 3: Mansão Knorr.

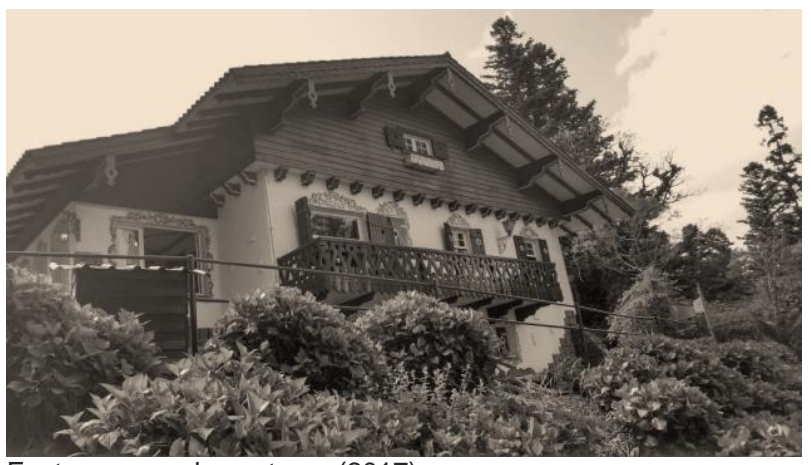

Fonte: acervo dos autores (2017).

Vale mencionar que Knorr é um personagem histórico de Gramado, diretamente vinculado ao setor turístico do município, sendo um dos idealizadores da Festa das Hortênsias ${ }^{1}$. Era integrante do Conselho de Turismo de Gramado, recebendo o título de Cidadão Gramadense "pelos valiosos serviços prestados ao nosso município" (GRAMADO, 1964). Ademais, infere-se que fosse um cidadão influente, tendo em vista que em sua mansão hospedaram-se diversas personalidades, dentre eles governadores, senadores, prefeitos, diplomatas, empresários, artistas, escritores, entre outros (KNORR, 1995).

Importa ressaltar que os imigrantes que fixaram-se na localidade onde atualmente é Gramado não eram oriundos da região da Bavária. Além disso, reconhece-se a diversidade cultural do território que compreende atualmente a Alemanha, no qual existe uma ampla diversidade regional. Entretanto, os imigrantes e seus descendentes reproduziram o estilo arquitetônico de tal região em Gramado, propagandose no município como forma de promover o turismo. Trata-se, portanto, de uma apropriação cultural que possui uma evidente conotação econômica.

Além disso, a inspiração germânica na paisagem de Gramado também pode estar relacionada à elite que adquiriu áreas de terras da herdeira de origem nobre Joaquina Rita Bier, filha de germânicos. O loteamento ocorreu no bairro Planalto na década de 1930, sob o comando do agrimensor Leopoldo Rosenfeld, alicerçado no conhecimento que adquiriu de cursos que frequentou na Europa e

\footnotetext{
${ }^{1}$ Evento considerado um marco na história do município, cuja primeira edição ocorreu em 1958. Originou outros eventos, que tornaram Gramado conhecida nacionalmente, como o Festival de Cinema e o Natal Luz.
} 
apresentou à vila uma nova perspectiva. Rosenfeld dividiu a área criteriosamente, respeitando a natureza e a topografia dos terrenos, tendo como premissa o embelezamento da cidade. As terras foram comercializadas predominantemente para europeus, especialmente germânicos que trouxeram para Gramado uma mentalidade europeia (SPARREMBERGER, 1995).

Cabe destacar que entre as décadas de 1920 e 1950 Gramado era destino de veranistas que se deslocavam, especialmente, de Porto Alegre, São Leopoldo e Novo Hamburgo em busca de um local reconhecidamente revigorante e cenário de saúde (BEHREND, 1999; DRECKSLER e KOPPE, 1999). Conforme Silva (2004) as viagens com caráter terapêutico iniciaram no século XIX, com a elite que buscava lugares aos quais atribuíam propriedade medicinais, tais como montanha e a costa marinha. Segundo a autora a relação entre terapia e lugares frios e altos teve origem em estudos científicos da Europa, no século XVIII, que foram propagados fortemente no Brasil. Tal panorama estimulou o estabelecimento do loteamento, que, por sua vez, aproximou ainda mais a alta sociedade a Gramado.

No que se refere ao PDDI, o primeiro apontamento quanto ao "estilo arquitetônico predominante" está registrado na alteração de 2006, contudo, ainda que a primeira menção a especificação oficial seja relativamente recente, infere-se que o estilo fora incentivado nas décadas anteriores. De acordo com Daros (2008), na década de 1970 já estava iniciando na cidade o "movimento bávaro", com alguns prédios construídos respeitando - estilo. Da mesma forma, na obra Gramado, simplesmente Gramado, elaborada pela Secretaria de Educação de Gramado em 1987, há menção a uma comissão designada pela administração municipal, cuja função é examinar os projetos das construções e sugerir quaisquer alterações necessárias para manter as características de Gramado.

Um exemplo para ilustrar a reconfiguração arquitetônica pela qual Gramado atravessou nas últimas décadas é o edifício do Palácio dos Festivais. Gramado é conhecida como a capital nacional do cinema devido ao Festival de Cinema que acontece desde 1973 no município. A atual sede do cinema e do referido Festival foi inaugurada em 1967 após o fechamento, em 1962, do único cinema existente na cidade.

O edifício do então Cine Embaixador [atual Palácio dos Festivais] foi construído, já com interesse turístico [tendo em vista que, de acordo com os registros de Daros (2008), o primeiro apelo foi feito por meio de ofícios, assinados pelo prefeito e pelo presidente do Conselho Municipal de Turismo], após mobilização da comunidade e veranistas, tendo em vista que a prefeitura não dispunha de condições para custear a edificação.

No final da década de 1980, já com o Festival de Cinema de Gramado consolidado e objetivando fortalecer o evento, o município iniciou a campanha "novo Embaixador", que, mais uma vez, apresentava a pretensão de angariar fundos com a comunidade, desta vez visando a ampliação e modernização do mesmo. Conforme Daros (2008), o remodelamento da estrutura permitiu aumento da capacidade de espectadores, atualização da parte técnica de som e imagem e expansão da área interna, ademais, houve a harmonização da edificação com 0 estilo arquitetônico de Gramado (Figura 4).

\section{Figura 4: Cine Embaixador (Década de 1980) e} Palácio dos Festivais atualmente.

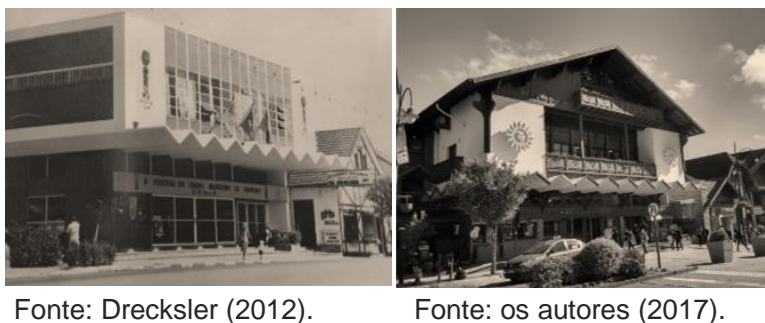

A releitura do exterior do prédio enquadrou a edificação no estilo bávaro que se propagava pela cidade (DAROS, 2008). O telhado, antes caracterizado por traços retos, foi remodelado, recebendo cobertura formada por duas águas, telhas de cerâmica e beiral. A fachada frontal exibe uma marquise em linhas quebradas que formam "Vs" invertidos, que se estende até a fachada lateral. A 
edificação recebeu uma sacada central rica em detalhes de madeira, bem como o restante da fachada. Nas duas extremidades do prédio, incorporou-se a face do Kikito [Símbolo e prêmio máximo concedido no Festival de Cinema de Gramado, criado pela artesã Elisabeth Rosenfeld (GRAMADO, 2017)] na fachada frontal.

Também no sentido de ilustrar o remodelamento que as edificações sofreram ao longo dos anos com o objetivo de caracterizar o município, apresenta-se, abaixo 0 edifício da Prefeitura Municipal de Gramado. Conforme a Imagem 5 [ao lado esquerdo] até a metade da década de 1980 o imóvel de dois pavimentos apresentava traços retilíneos, telhado de duas águas com intersecção central rebaixada. $\mathrm{Na}$ fachada frontal veem-se três janelas retangulares, alinhadas no sentido horizontal no segundo pavimento. O primeiro pavimento contém três portas estreitas, intercaladas por três janelas gradeadas.

Em 1986 a nova edificação foi concluída (Figura 5), enquadrada no estilo bávaro. Nitidamente assemelhando-se com a Mansão Knorr, o edifício possui gabarito baixo, comporta dois pavimentos e é abundante em detalhes de madeira, iniciando no subtelhado, que é revestido em madeira e beiral ornado com lambrequim. As aberturas são em madeira e contornadas por tijolos a vista; as janelas possuem formato de retângulo com as bordas arredondas enquanto as portas têm contorno de arco. A fachada frontal possui uma ampla sacada que se estende até a fachada lateral esquerda.

\section{Figura 5: Prefeitura Municipal de Gramado} década de 1970 e 2017.

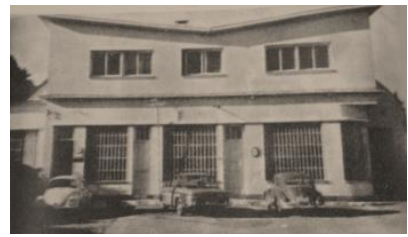

Fonte: Drescker (2012).

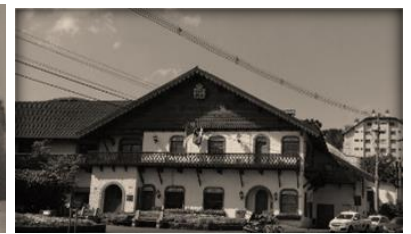

Fonte: acervo dos autores.
Nesta mesma perspectiva, apresentamos a edificação do Banco do Brasil. Embora a referida instituição tenha iniciado suas atividades em
Gramado em 1964, a nova sede, localizada em uma esquina nobre de Gramado, estava sendo edificada na década de 1970 apresentando linhas modernas, seguindo o padrão estabelecido pelo Banco. O poder público se mobilizou a fim de enquadrar a construção no estilo que se difundia na cidade e, após esforços para receber em Gramado o diretor da $6^{\circ}$ Região do Banco do Brasil, houve a autorização para a modificação da arquitetura, personalizando o prédio de acordo com o estilo bávaro (DAROS,2008). Tal feito foi repetido na construção do Bando do Estado do Rio Grande do Sul (BANRISUL), cuja arquitetura também é diferenciada das demais agências estabelecidas no estado.

Embora a sede do Banco do Brasil tenha sofrido alterações desde então, o estilo bávaro ainda predomina na edificação (Figura 6).

Figura 6: Sede do Banco do Brasil estilizada em Gramado.

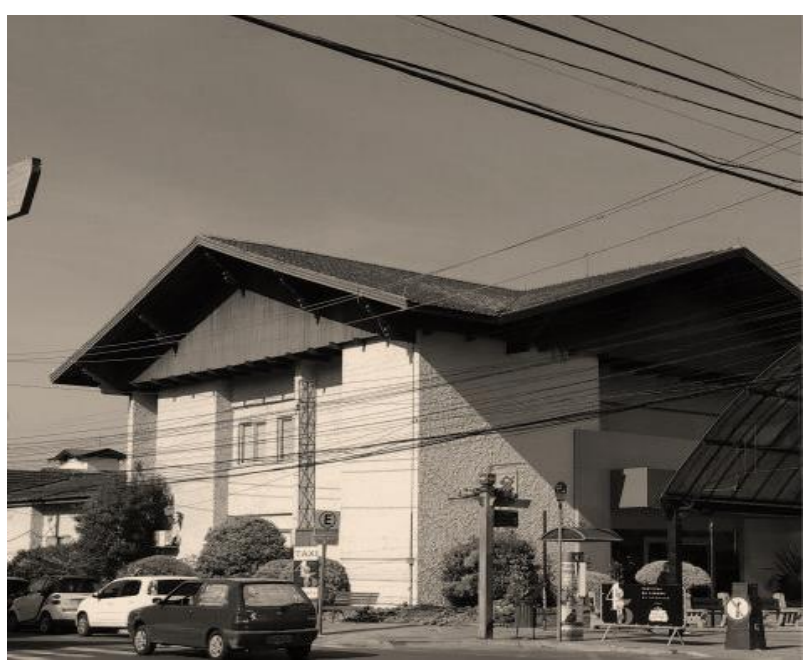

Fonte: acervo dos autores (2017).

O estilo bávaro também é reproduzido na Central de Informações ao Turista, inaugurada no final da década de 1970. O prédio segue o estilo bávaro - que inspira o estilo arquitetônico de Gramado-, telhado inclinado produzido com cerâmica e beirado ornado com lambrequim em madeira. $\mathrm{Na}$ fachada lateral [que é frente para a Avenida Borges de Medeiros] o subtelhado [sótão até o forro] em madeira escura apresenta o brasão do município. Logo abaixo uma larga porta dá acesso à sacada, com parapeito em madeira, as janelas são 
retangulares com os cantos arredondados, envolvidas com tijolos a vista.

O primeiro pavimento comporta o sanitário público, a parte externa é coberta por pedra, material natural sugerido pelo PDDI para as construções no estilo arquitetônico predominante de Gramado (Figura 7).

\section{Figura 7: Central de Informações ao Turista} (2017).

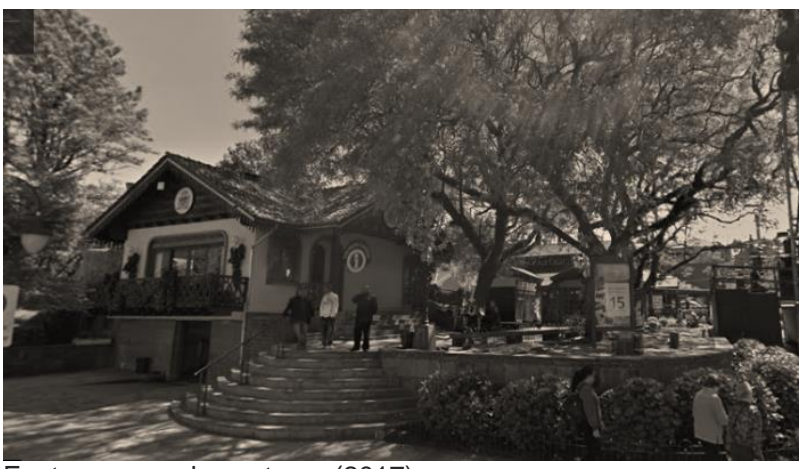

Fonte: acervo dos autores (2017).

O estilo bávaro também inspirou a arquitetura de equipamento de hospedagem de alto padrão. Localizado na intersecção entre a Avenida das Hortênsias e a Avenida Borges de Medeiros, hotel Serra Azul configura-se como um tradicional e luxuoso equipamento hoteleiro do município, em que o valor da estadia pode custar até 1.000 reais. De acordo com o website do próprio hotel, a infraestrutura compreende 152 apartamentos, piscina térmica com vestiários climatizados, sauna, spa, múltiplas salas [jogos, internet, televisão], entre outras áreas de lazer. Ademais, o hotel possui um centro de eventos com capacidade para 1.300 pessoas, salas de apoio, camarins entre outros (Figura 8).

\section{Figura 8: Hotel de alto padrão em estilo bávaro} em Gramado (2017).

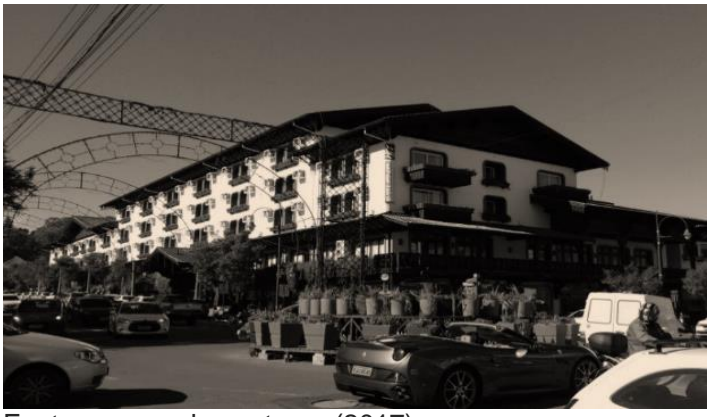

Fonte: acervo dos autores (2017).
O térreo é configurado como galeria, composta por 9 lojas, especialmente do ramo do vestuário. $\mathrm{O}$ segundo pavimento comporta as salas de entretenimento, o centro de eventos, a recepção e alguns apartamentos, os outros dois pavimentos são constituídos de apartamentos. O prédio, inspirado no estilo bávaro, tem janelas e vitrines retangulares de cantos arredondados, contornadas com tijolos a vista e ornadas com floreiras em madeira.

Outro exemplo revelador é o edifício da rodoviária do município. Reconstruído na década de 1980, e também valendo-se do estilo bávaro como inspiração, a construção apresenta madeira e pedra em abundância. O edifício que abriga a rodoviária é, sem dúvida, um dos mais significativos do espaço urbano de Gramado, sendo a porta de entrada e saída de inúmeros turistas e moradores da cidade, que utilizam o transporte coletivo como meio de transporte. Cabe ressaltar, ainda, que a rodoviária localiza-se junto à Praça das Etnias, que é outro ponto de destaque na cena urbana de Gramado. Nesta praça foram construídas três réplicas de residências, que procuram contar parte da história da arquitetura imigrante no município. A casa germânica, italiana e portuguesa, dispostas na praça, representam, simbolicamente, a herança cultural dos imigrantes, que fundaram o município (Figura 9).

Figura 9: Rodoviária de Gramado (2017).

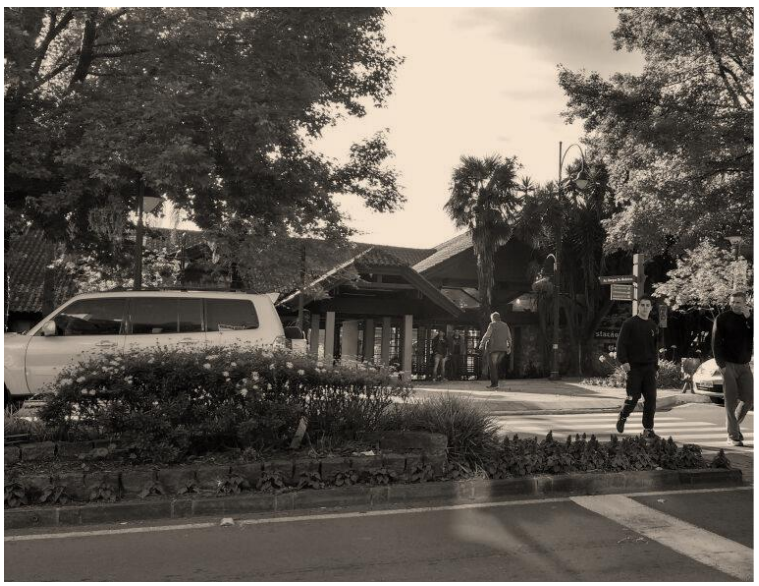

Fonte: acervo dos autores (2017).

No entanto, não é somente o estilo bávaro que se destaca na morfologia urbana gramadense. A inspiração no enxaimel pode ser percebida em diversas construções, que abrangem prédios 
comerciais, residenciais, equipamentos turísticos e edifícios religiosos, como é o caso da Igreja Metodista de Gramado (Figura 10).

Figura 10: Igreja com inspiração enxaimel.

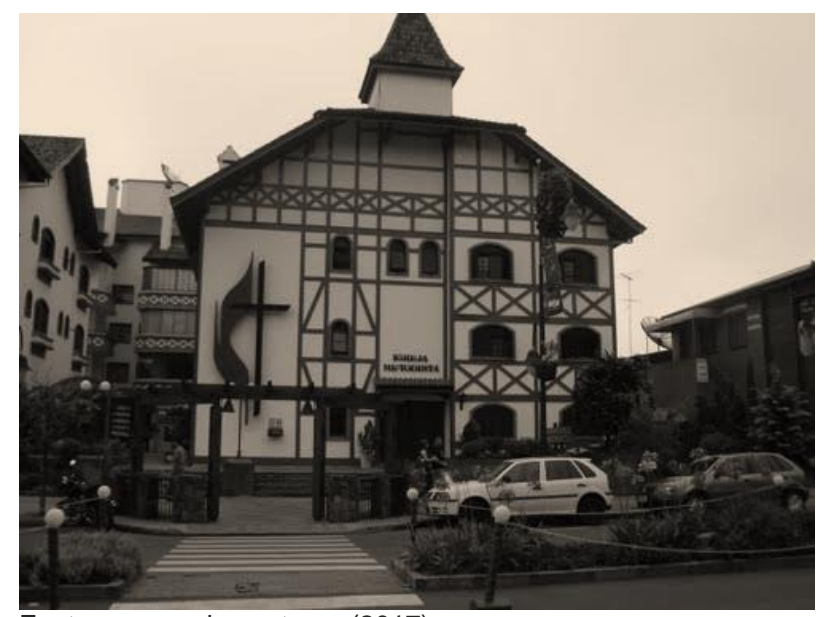

Fonte: acervo dos autores (2017).

Segundo Weimer (2005), conforme citado por Sattler (2011), o enxaimel seria, em português, o que os germânicos chamam de "Fachwerkbau", que na tradução literal remeteria a "construção em prateleiras", fazendo referência a técnica de construção em que diversas peças são encaixadas, formando uma estrutura heterogênea. $O$ autor menciona, ainda, que as casas de enxaimel eram propriedades de classes de maior poder aquisitivo.

\section{Considerações finais}

Neste estudo, buscou-se discutir acerca da influência da imigração italiana e germânica na arquitetura do bairro Centro do município de Gramado. Para tanto, o procedimento metodológico compreendeu, inicialmente, coleta de informações acerca da imigração italiana germânica e italiana no Brasil, por meio de revisão bibliográfica. Em seguida, visando mapear as edificações que seriam selecionadas para o estudo executou-se a visita de campo, na qual foram eleitas 10 edificações. $\mathrm{Na}$ oportunidade, adotando-se a observação sistemática, realizou-se os registros fotográficos dos lotes em análise. A fonte documental envolveu registros das obras que narram a história do município [elaboradas por moradores de Gramado].
A pesquisa permitiu constatar que a cenografia do centro de Gramado está direcionada para a reprodução do estilo europeu. Mais especificamente, embora a migração italiana tenha sido mais expressiva na região, percebe-se uma busca, particularmente por parte da municipalidade, de uma identidade arquitetônica vinculada à etnia germânica. Tal panorama é repercutido no PDDI do município, que, por meio de normas e diretrizes, direciona as obras ao estilo arquitetônico predominante de Gramado, cujas especificações, ainda não oficiais, recomendam o uso de materiais naturais, como pedra e madeira.

A influência germânica no direcionamento da estética citadina parece estar atrelada a elite germânica que adquiriu terras em Gramado particularmente após a década de 1930. O estilo bávaro, difundido na cidade especialmente após a década de 1970 e considerado pelo poder público como o "estilo das casas de Gramado", tem como referência a Mansão Knorr, construída por Oscar Knorr, filho de descentes germânicos e personalidade influente no segmento turístico de Gramado na década de 1940.

Observa-se que o estilo bávaro e outras ramificações da arquitetura germânica, como o enxaimel, são inspirações para edificações de diversos usos, tais como as que abrigam hotéis, pontos turísticos, igrejas, instituições públicas e privadas, entre outras. No entanto, ainda que a identidade difundida elegida pelo município seja germânica. Mesmo que a inspiração germânica seja preponderante na arquitetura na área central de Gramado, ainda são perceptíveis características arquitetônicas italianas na área em estudo.

\section{Referências}

BRASIL. Ministério do Turismo. Gramado (RS) aposta na expansão do turismo de negócios. 2015. Disponível em: http://www.turismo.gov.br/\%C3\%BAltimasnot\%C3\%ADcias/5109-gramado-(rs)-apostana-expansao-do-turismo-denegocios.html>.Acesso em: 12 set. 2016. 
DAROS, Marilia. Grãos: coletânea histórica. 2008.

DRECKSLER, Carlos Gilberto. Gramado Contrastes. Porto Alegre: Evangraf, 2012.

DRECKSLER, Carlos Gilberto; KOPPE, Iraci Casagrande. Era uma vez... Gramado: Nogbeck, 1999.

GRAMADO. Secretaria Municipal de Educação. Gramado, simplesmente Gramado. Gramado, 1987.

GRAMADO, Secretaria de Planejamento, Urbanismo, Publicidade e Defesa Civil de Gramado. Características arquitetônicas predominantes. [mensagem pessoal] Mensagem recebida por: <francieleberti@hotmail.com>. em: 13 ago. 2017.

GRAMADO (Município). Constituição (1975). Lei no 3296.75 de 21 de julho de 2014. Dispõe sobre o desenvolvimento urbano e rural do município de gramado, institui o novo plano diretor de desenvolvimento integrado (pddi), e dá outras providências. Disponível em: < https://goo.gl/7JnFKf >. Acesso em: 12 ago. 2017.

GRAMADO (Município). Constituição (1964). Lei no 165, de 14 de abril de 1964. Concede Título de Cidadão Gramadense à Pessoas,por Serviços Prestados a Gramado. Disponível em: <https://goo.gl/VXTL9d>. Acesso em: 23 ago. 2017.

HERÉDIA, Vânia Beatriz M. A imigração européia no século passado: o programa de colonização no Rio Grande do Sul. Scripta Nova: revista electrónica de geografía y ciencias sociales, v. $5,2001$.

IBGE (INSTITUTO BRASILEIRO DE GEOGRAFIA E ESTATÍSTICA). Censo Demográfico 2010. Disponível em:. Acesso em: 12 set. 2016.

IOTTI, Luiza Horn. Imigração e colonização: legislação de 1747 a 1915. EDUCS, 2001.

JORNAL DE GRAMADO. Abandonada, casa pode ter outro destino. Jornal de Gramado. Gramado, p. 1-1. out. 2015. Disponível em: <goo.gl/G2jUUi>. Acesso em: 23 ago. 2017.

KNORR, Ilga Korndorfer. Parque Knorr: Por um ideal. In: DAROS, Marilia; BARROSO, Vera Lucia Maciel (Org.). Raízes de Gramado: 40 anos. Gramado: Est, 1995. p. 108-114.

KNORR, lara.A identidade cultural de Gramado. In: DAROS, Marilia; BARROSO, Vera Lucia Maciel (Org.). Raízes de Gramado: 40 anos. Gramado: Est, 1995. p. 137-150.

RIGATTI, D. O turista, o morador e o uso do espaço urbano: interações espaciais em Gramado e
Canela. Paisagem e Ambiente, n. 16, 2002. p. 69-107.

ROCHE, Jean. A colonização germânica e o Rio Grande do Sul. Editora Globo, 1969. 